\title{
ОСОБЕННОСТИ ОБУЧЕНИЯ И МОТИВАЦИИ СТУДЕНТОВ ПРИ ДИСТАНЦИОННОМ ИЗУЧЕНИИ ИНОСТРАННОГО ЯЗЫКА В ВУЗЕ
}

\section{FEATURES OF TRAINING AND MOTIVATION OF STUDENTS IN DISTANCE LEARNING OF A FOREIGN LANGUAGE AT A UNIVERSITY}

\section{G. Yanovskaya}

Summary: The article deals with issues related to the features of teaching and motivation of students in distance learning of a foreign language at a University. Actuality of the work is due to the fact that in modern conditions of active use of distance learning in higher education institutions, teachers face tasks that are relevant both for the current time and for the future development of the educational industry, which open up opportunities for developing methods and updating practical teaching skills. In addition to the broadest opportunities for individual cognitive work of students, technological innovations in remote teaching have many advantages. The article describes the issues of distance learning of students in the specialty «Foreign language», the complexity of implementing some types of classroom work is noted. Taking into account the presented data, the author formulates another problem of distance education - it implies active and motivated participation of the student in the process. In this connection, the factors of increasing students' motivation are presented.

Keywords: distance learning, foreign language, student motivation, video conference, technical training tools, continuing education.

\author{
Яновская Галина Самойловна \\ старший преподаватель, Московский авиационный \\ институт (национальный исследовательский \\ университет) \\ popovski2003@mail.ru
}

Аннотация: В статье рассматриваются вопросы, связанные с особенностями обучения и мотивации студентов при дистанционном изучении иностранного языка в Вузе. Актуальность работы обусловлена тем, что в современных условиях активного использования дистанционного обучения в высших учебных заведениях перед преподавателями стоят задачи, актуальные как для нынешнего времени, так и для будущего развития образовательной отрасли, которые открывают возможности для развития методик и обновления практических навыков преподавания. Помимо широчайших возможностей для проведения индивидуальной познавательной работы обучающихся, технологические инновации в удаленном преподавании имеют множество преимуществ. В статье описаны вопросы дистанционного обучения студентов по специальности «Иностранный язык», отмечаются сложность реализации некоторых видов аудиторной работы. Учитывая представленные данные, автор формулирует еще одну проблему дистанционного образования - оно подразумевает активное и мотивированное участие студента в процессе. В связи с чем представлены факторы усиления мотивации студентов.

Ключевые слова: дистанционное обучение, иностранный язык, мотивация студентов, видеоконференция, технические средства обучения, непрерывное образование.
Д истанционный формат обучения, вызванный мировой пандемией, стал серьезным испытанием для сферы образования. Методисты и преподаваыли вынуждены решать проблемы, возникающие в процессе перехода на дистанционный формат обучения, в максимально сжатые сроки. Прошедший учебный год позволил испытать нововведения - сервисы для видеоконференций, где проводятся семинары и онлайнвстречи с учащимися. Такой опыт бесценен в социокультурном аспекте, поскольку влияет на трансформацию моделей поведения, стереотипов, а также отношений между людьми. Перед учеными современного мира стоят задачи, актуальные как для нынешнего времени, так и для будущего развития образовательной отрасли, которые открывают возможности для развития методик и обновления практических навыков преподавания [6, с.41].

Возможность скомбинировать традиционное преподавание с электронным обучением уже приносит ощутимые результаты. Дистанционные технологии - это не только самостоятельная работа студентов, но и обяза- тельные «очные» занятия, осуществляемые при помощи электронных сервисов [1, с.36]. В данном случае можно разделить практические занятия на два типа:

- индивидуальные по схеме «задание - контроль», когда учащийся самостоятельно выполняет и сдает полученное от преподавателя задание;

- групповые по схеме «видеоконференция - онлайнсеминар», схожий по методике с очным занятием. Обучающиеся активно взаимодействуют друг с другом, могут объединяться в группы в виртуальных комнатах для решения поставленных задач, а также общаться с преподавателем без временной задержки как в рамках группы, так и индивидуально. Так же применяются средства видео- и аудиосвязи, текстовые чаты и форумы [5. С.355].

В рамках изменившейся системы образования стало необходимым сформировать такую мотивацию для решения познавательных задач обучения, в которой информационные технологии будут выполнять в том числе организационную функцию, обеспечивая коммуникацию 
между участниками образовательного процесса и решая вопрос поиска необходимых данных.

Помимо широчайших возможностей для проведения индивидуальной познавательной работы обучающихся, технологические инновации в удаленном преподавании имеют и множество преимуществ:

- необходимая информация может быть мгновенно получена любым учащимся, независимо от его географического положения;

- формируется индивидуальный подход к каждому учащемуся, чего невозможно достичь при традиционной форме преподавания;

- появляется возможность исследовать объекты интерактивно, что на аудиторных занятиях чаще всего невозможно технически;

- образование становится более насыщенным по ритму постановки задач и интенсивным, т.к. многие действия автоматизируются;

- возможен регулярный объективный контроль со стороны преподавателя и самоконтроль в индивидуальной работе учащегося. К сожалению, внедрение в дидактический процесс технологических средств до сих пор не является систематическим и регулярным, неся, преимущественно, вспомогательную функцию. Создание новых методик, включающих дистанционный способ обучения, является приоритетным для ученых и практикующих педагогов на данный момент [8, с.35].

Исследователи С.Ю. Галицкая и А.О. Назарова, занимающиеся вопросами дистанционного обучения студентов по специальности «Иностранный язык», отмечают сложность реализации некоторых видов аудиторной работы. Прежде всего, это традиционный "warming up", проводящийся в самом начале занятия, - упражнение для тренировки спонтанной неподготовленной речи. В условиях очного взаимодействия преподаватель задает учащемуся вопросы на разные тематики, не давая практически никакой возможности раздумывать над ответами. Использование технических средств существенно влияет на скорость такого опроса из-за несовершенства аппаратуры (микрофон), а также скорости интернет-соединения. Все это создает нервную обстановку, которая демотивирует обучающихся в их стремлении к новым знаниям. Кроме того, от дистанционной формы занятий страдают и дискуссии на иностранном языке. Зачастую учащиеся, получив вопрос или тему для разговора, начинают перебивать друг друга, не слышать оппонента, или все вместе замолкают. Микрофоны, включенные в рамках онлайн-занятия у всех одновременно, тоже искажают звук, что в целом влияет на понимание цели общей работы $[2$, с.30].

По мнению Н.М. Масютиной, затруднениями в изучении дисциплины «Иностранный язык» является тре- вожность учащихся, а также их сомнения в уровне собственных знаний. Соединяясь с большими объемами информации и неоднородностью познания иностранного языка, эти факторы влияют на основную дидактическую сложность заявленной проблемы - недостаточную методическую оснащенность преподавателей, не сумевших пока перенести свои наработки в новые условия. Для эффективной борьбы с этой негативной тенденцией необходимо сформировать углубленные навыки индивидуальной работы у студентов - познакомить их с ознакомительным, изучающим и поисковым видами чтения, рассказать о ресурсах электронных словарей и библиотек как в сети Интернет, так и присоединенных к курсу в рамках образовательной платформы [4, с.187].

Осуществляя учебный процесс в дистанционном формате, преподаватели заметили присутствие некоторых психологических трудностей у своих студентов, а, следовательно, падающую результативность. Стоит отметить, что студенты, проявлявшие потребность к самоактуализации и стремившиеся к знаниям и личностному росту, сохранили увлеченный подход к обучению, невзирая на изменившиеся условия. Сложности наблюдаются у недостаточно мотивированных учащихся, успехи которых были труднодостижимы и во время классической аудиторной работы. Такие студенты чаще демонстрируют несоответствующие целям высшего образования стремления к познанию, оправдывая свой низкий уровень самоорганизации техническими проблемами, возникающими не по их вине. Подобный подход к дистанционному обучению препятствует развитию необходимых профессиональных компетенций и снижает качество подготовки [9, с.281].

Учитывая эти доводы, можно сформулировать еще одну проблему дистанционного образования - его отличие от очного обучения подразумевает активное и мотивированное участие студента в процессе. Для достижения необходимых результатов он должен иметь высокий уровень самоорганизации и мотивации. Но именно преподаватель может обеспечить позитивное отношение учащихся к своим обязанностям, используя собственные методические разработки - например, подавать материал в удобной форме, стимулировать к самостоятельному поиску информации, регулярно давать обратную связь и оценку деятельности каждого студента. Создание высокого уровня мотивации выходит на первый план в современном образовании в рамках задач, которые решает каждый педагог в дистанционном обучении. Успешное и качественное образование с использованием технологий возможно с учетом качественных методик, доступных информационных и учебных материалов, самоорганизации участников и их стремления к достижению положительного результата [3, с.10].

Обязательным фактором усиления мотивации каждо- 
го учащегося является достижение и поддержание компетентности. Преподаватель должен быть достаточно компетентен, чтобы объяснить новую учебную задачу, а студент - чтобы решить ее. Положительного результата в дистанционной работе можно добиться, только улучшая пользовательский интерфейс образовательных платформ, делая его понятным и простым. Говоря о возможностях аудио- и видеоконференций в формате Zoom, нужно заметить, что для разумного потребления времени и энергии в ходе занятия до начала выполнения задания каждое действие должно требовать не более 2-х кликов. Для эффективного распределения учебного времени преподавателю должно быть необходимо использовать в объяснении задания не более 2-3 предложений. Если этого недостаточно, то задание необходимо адаптировать под учащихся. С психологической точки зрения восприятие студентами преподавателя, хорошо владеющего возможностями онлайн-платформ, положительнее.
Есть дополнительный повод заинтересовать учащихся функционалом образовательной площадки - некоторые студенты могут стать преподавателями в будущем, а значит, уже будут знакомы с технологической стороной работы и подготовлены к подобной деятельности [7, с.16].

Говоря об организации процесса обучения иностранному языку в вузе в дистанционном формате, стоит заметить, что именно такой подход помогает сделать акценты на личности учащегося, его развитии и самосовершенствовании. Этот факт является частью концепции непрерывного образования, позволяющего достичь профессиональных высот. Кроме того, изучение иностранного языка требует регулярности, ее роль так же важна в упомянутой образовательной парадигме. Дистанционное обучение в данном случае делает более доступным формы научно-исследовательской активности и оптимизирует учебно-познавательный процесс.

\section{ЛИТЕРАТУРА}

1. Арбузов С.С., Константинов А.Н. Использование стрим-технологий в образовательном процессе при обучении студентов в дистанционной форме//Педагогическое образование в России. 2018. № 8. С. 34-41.

2. Галицкая С.Ю., Назарова А.О. Из опыта дистанционного преподавания английского языка/В сборнике: Основные вопросы лингвистики, лингводидактики и межкультурной коммуникации. сборник трудов XI международной научно-практической конференции. 2020. С. $29-33$.

3. Гельман В.Я. Проблемы перехода на дистанционное обучение//Alma mater (Вестник высшей школы). 2020. № 7. С. 8-12.

4. Масютина Н.М. Перспективы и сложности дистанционного изучения иностранного языка//Проблемы современного педагогического образования. 2020. № 68-1. С. 187-189.

5. Нутаева А.В. Практика дистанционного обучения в высшей школе //Современные наукоемкие технологии. 2020. № 6-2. С. 353-357.

6. Садыкова Р.Х. Дистанционное обучение студентов: реалии и опыт// Научно-методический электронный журнал Концепт. 2020. № 9. С. 41-56.

7. Сетличная С.А. Онлайн-платформа как фактор повышения мотивации студентов лингвистического профиля при дистанционном обучении/В сборнике: Теория и практика современной педагогики. Сборник статей Международной научно-практической конференции. - Пенза, 2020. С. 16-18.

8. Ставцева И.В., Карманова А.Ф. Разработка и применение онлайн сопровождения обучения практической грамматике английского языка// Вестник Южно-Уральского государственного университета. Серия: Лингвистика. 2016. Т. 13. № 4. С. 32-39.

9. Танцура Т.А. Проблема мотивации студентов к изучению иностранного языка в период перехода на дистанционный формат обучения//Мир науки, культуры, образования. 2020. № 3 (82). С. 281-282.

(с) Яновская Галина Самойловна (popovski2003@mail.ru). 